\title{
CLIMATE CHANGE AND ECONOMIC FACTORS WHICH AFFECT ON WHEAT CROP PRODUCTIVITY IN EGYPT
}

\author{
M.M.M ABD EL-AZIZ \\ Central Laboratory for Agricultural Climate, ARC, Giza
}

(Manuscript received 26 February 2018)

\begin{abstract}
$\mathrm{E}$ gyptian what represent most important winter crop and the bread produced from it is the important commodities for Egyptian people in daily food. Egypt import about 9.95 million ton for facing the gap between consumption and production which is about 9.64 million ton in 2016. Subsidy represented at least $70 \%$ from the value of food subsidies which over 22.442 billion Egyptian pound in 2016. The study aimed to measuring the impact of general equation for the climate factors (Maximum Temperature, minimum temperature and average of relative humidity) in the growth months of wheat crop. Study also determined the relationship between climatic factor, the critical month and the yield, with measuring the economic impacts of climatic factor with yield on the farm level and national level. The results from measuring the relationship between yield of wheat and minimum temperature showed that each increase in minimum temperature with one degree lead to decreasing in the yield with 0.11 per feedan, with statistical significant, $T$ calculated was -4.37 , while determination coefficient indicated to around $42 \%$ of the changes in the yield due to the changes in minimum temperature in April. Results showed also there are some scenarios showed the effect of minimum temperature changing on the yield, which made effects on revenues and quantity and value of imports. Finally the study recommended the importance of collecting and analyzing climate data at the level of the districts, governorates and the republic, while making them available to researchers, Change the crop map of different crops in the light of changes in climatic factors or those expected to occur and Preparing programs to cultivate the varieties of crops that are resistant to heat tolerance and that the financing of these programs is sufficient to accelerate the emergence of expected new varieties.
\end{abstract}




\section{التغيرات المناخية والعو امل الاقتصادية المؤثرة على إنتاجية محصول القمح فى مصر القع} محمد متولى محمود عبد العزيز

$$
\text { المعدل المركزي للمناخ الزراعي - مركز البحوث الزراعية - جيزه }
$$

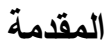

هناك الكثير من العو امل نؤثز على إنتاجية محصول القمح، كما أن هناك العديد من العوامل

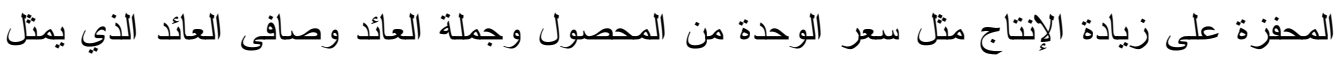
ربح المنتج، كما قد يتأثر منتوسط الإنتاج سلبا بارتفاع تكاليف الإنتاج خاصة في ظل محدودية مئل ميز انية

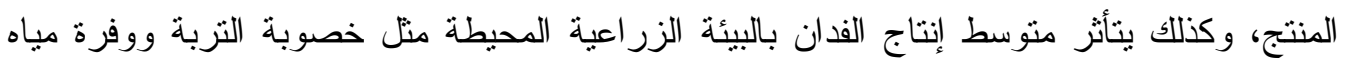
الري، وتو افر طريقة للصرف، وتوفير مستلزمات الإنتاج خاصة الحديثة والمناسبة وبالكميات

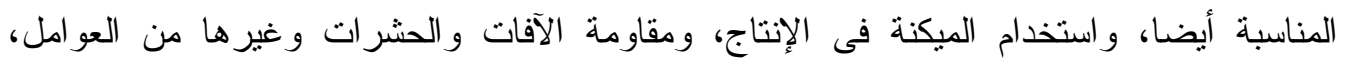

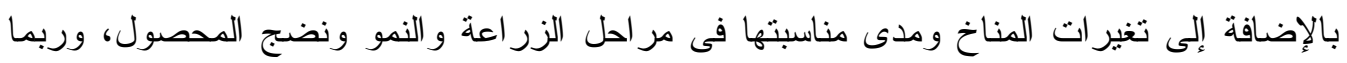

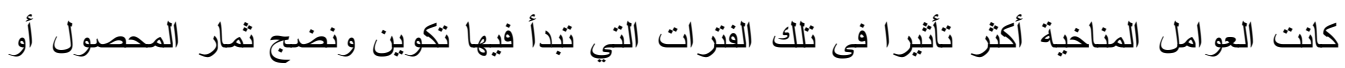
يعرف بأطوار النضج، حيث تؤثر بشكل كبير فى عدد ووزن الثمار، و هو ما يؤثر فى جودة وكمية الإنتاج، مع الأخذ فى الاعتبار الصنف المزروع من المحصول ومدئر ومدى ملائمته لموقع الإنتاج

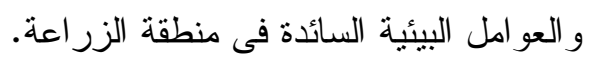

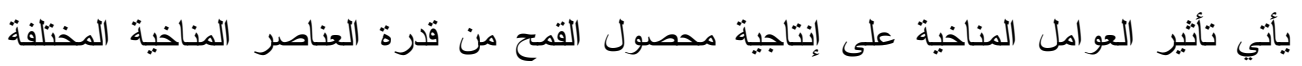
التأثنر على مر احل نضج المحصول، وكل مرحلة تحتاج إلى مستوى يناسبها من درجات الحرارة

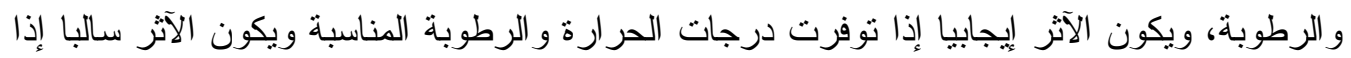
لم تتوفر ظروف المناخ المناسبة لنطور تللك المراحل، وعموما فإنه يمكن تقسيم دورة حياه نبات

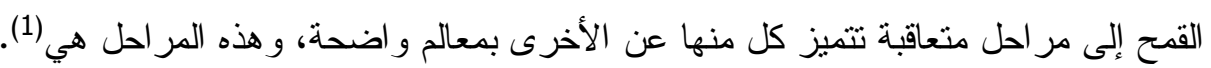
(أ) مرحلة ما قبل العلم Pre flag stage: حيث تكون ورقة العلم غير ظاهرة، ولا توجد أب ولي انتقاخات على سيقان النبات. (ب) مرحلة العلم (مرحلة الغمد الأولى) Early Boot flag stage: وتنتيز بأن طوق ورقة العلم يظهر أعلى طوق الورقة النبتية ،وتكون السنبلة المحاطة أسفل طوق الورقة النبتية.

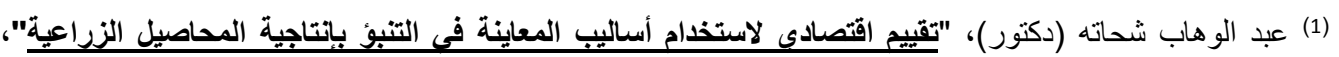

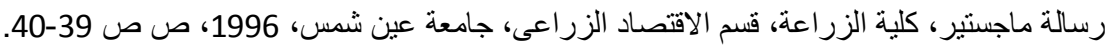


مرحلة الغمد المتأخر (مرحلة التزهير) Lote Boot Or Flower Stage: وتتميز بانتفاخ

السنبلة الدحاطة أعلى طوق الورقة النبتية ويكون محتوى السنابل عبارى عن سائل مائى . مرحلة الطور اللبنى Milk Stage : اهم ما يميز ها ظهور الحبوب داخل العصافات، فيكون

$$
\text { محتوى الحبوب سائل لبنى رطب وتكون الحبوب لينة ورطبة. }
$$

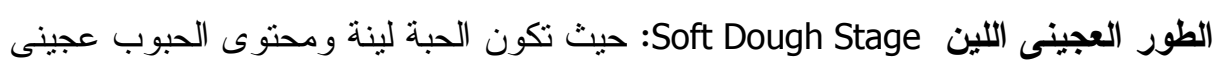

(و) الطور العجينى الصلب Hard Dough Stage:

كسر ها ولكن يصعب طحنها.

(ز) طور النضج الكامل Pipe Stage: حيث تكون الحبوب صلبة ومتماسكة ، ويمكن تكسير ها

إلى قطع ويمكن طحنها وتحويلها إلى دقيق.

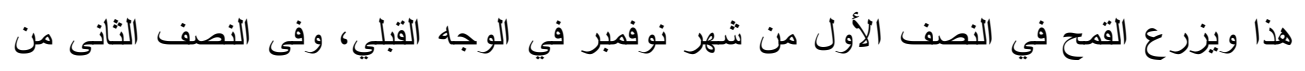

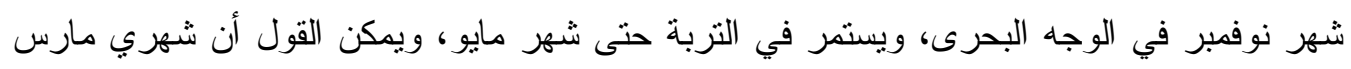

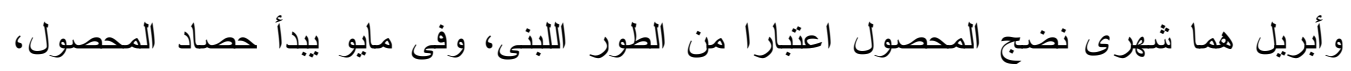
وربما يبدأ في أو اخر أبريل في الوجه القبلي.

\section{مشكلة الدر اسة}

يمنل القمح أهم الحاصلات الثتوية علي الإطلاق، ويعتبر الخبز الناتج هو الغذاء الأساسي للسود

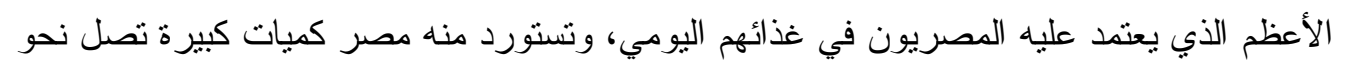

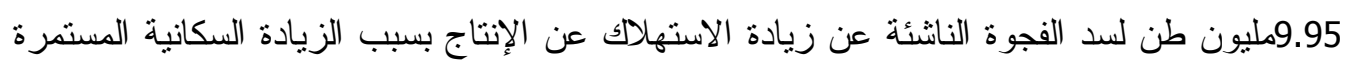

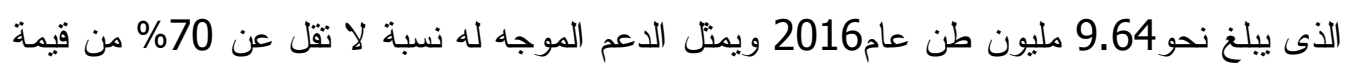
الدعم الغذائي و الذي تعدي 22.442 مليار جنية عام 2016، وتكمن مشكلة الدراسة في:

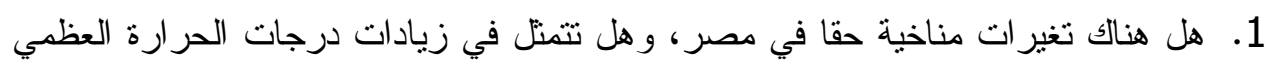

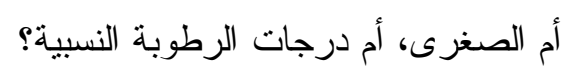

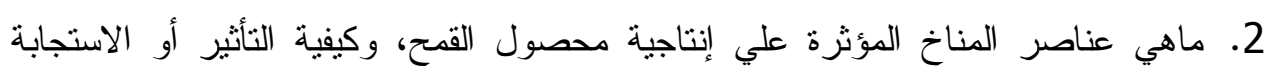
للتغير ات المناخية في شكل نقص أو زيادة في الإنتاجية الفدانية؟

$$
\text { أهداف الدر اسة الدة الإن }
$$

1 . قياس الاتجاه العام لإنتاجية المحصول.

2. قياس الاتجاه العام لعناصر المناخ (درجة الحرارة العظمي، درجة الحرارة الصغرى، منوسط درجة الرطوبة النسبية) وذلك في شهور التأثير علي إنتاجية المحصول. 3. اختيار العنصر المناخي الحرج للمحصول. 4. اختيار الثهر الحرج لإنتاجية المحصول.

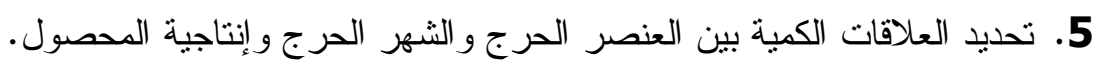


6. قياس الآثار الاقتصادية المتوقعة لعلاقة التغير ات المناخية و إنتاجية المحصول علي مستوي المزر عة و علي المستوي القومي.

\section{الطريقة البحثية}

تستخدم الدراسة طرق التحليل الوصفي والكمي لتحقيق أهداف الدراسة، مع التركيز علي الطرق لبحنه

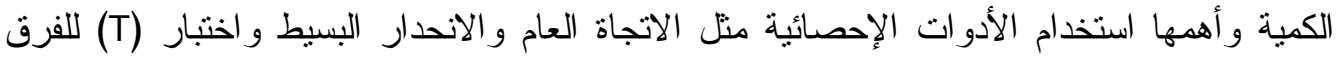
بين متوسطين وغيرها من أدوات التحليل المناسب، بالإضافة إلي بعض تلطبيقات النظرية الاقتصادية.

\section{نتائج الاسراسة}

1. قياس الاتجاه العام لإنتاجية محصول القمح خلال الفترة (2017-1990):

تتشير المعادلة التالية إلى نتائج قياس الاتجاه العام لمتوسط إنتاجية القمح في مصر خلال الفترة (2017-1990) ولمدة 27 عاما، ويتضح من المعادلة أن إنتاجية محصول القمح تحقق على لئى الأقل 2.31 طن في الفدان، فإنها تزيد سنويا بنحو 0.021 طن، وأن هذه الزيادة معنوية إحصائيا حيث

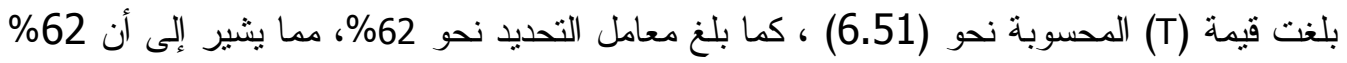

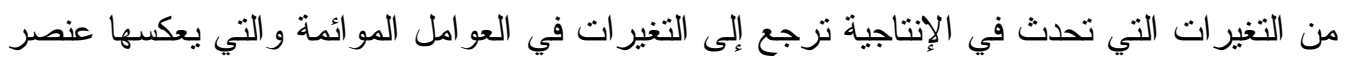
الزمن، كما تتثير قيمة (F) المحسوبة (42.41) إلى صلاحية ندوذج الانحدار الخطى في تمثيل العلاقة بين المتغيرين. - مبن $\hat{y}=2.31+0.021 X_{i}$

$R^{2}=(0.62)$ $F=42.41$ حيث : (1)

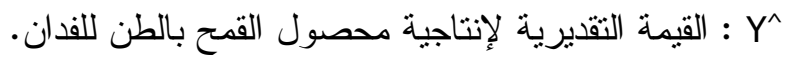
Xi وحدات الزمن بالسنو ات من 1 إلى 27 سنة . 2. قياس الاتجاه العام لعناصر المناخ المختلفة: م قياس الاتجاه العام لارجة الحرارة العظمى لشهر مارس.

تشرح المعادلة التالية نتائج قياس الاتجاه العام لدرجة الحرارة العظمى في شهر مارس خلال الفترة (1990-2017)، ويتضح من المعادلة أن هنالك زيادة سنوية نقدر بنحو 0.166 درجة في شهر

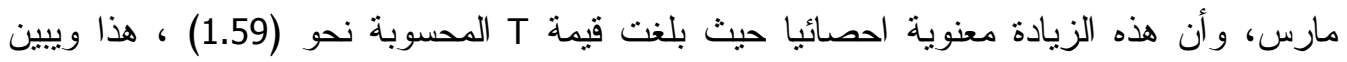

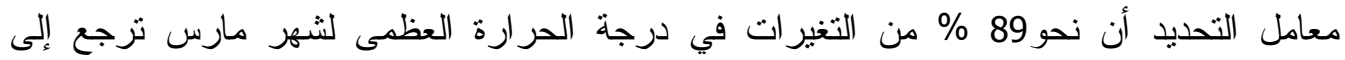
التغيرات التي يعكسها عامل الزمن ، ونتشير قيمة F المحسوبة و المقدرة بنحو (2.53) إلى معنوية نموذج الانحدار الخطى وصلاحيته لتمثيل العلاقة بين المتغيرين التابع و المستقل. $\hat{y}=24.47+0.166 X_{i}$ 


$$
\mathrm{R}^{2}=(0.89) \quad \mathrm{F}=2.53
$$

\section{حيث :}

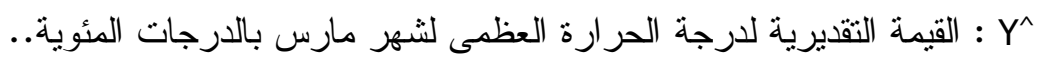
: وحدات الزمن بالسنو ات من 1 إلى 27 سنة .

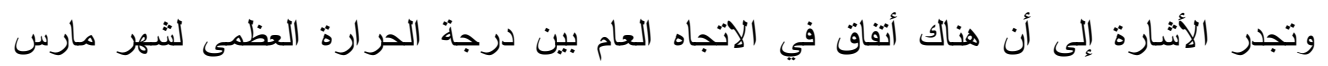

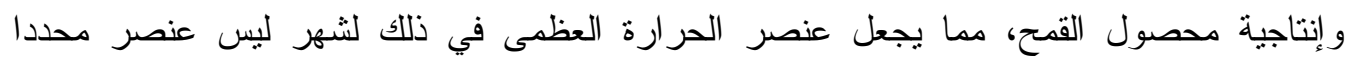

\section{م قياس الاتجاه العام لارجة الحرارة العظمى لشهر أبريل.}

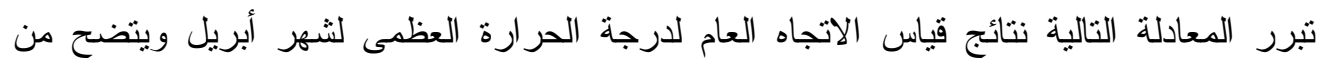
المعادلة أن هنالك زيادة معنوية احصائيا تقدر بنحو 0.118 درجة مئوية سنويا، وأن هذه الزئه الزيادة

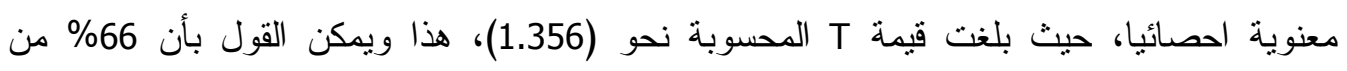

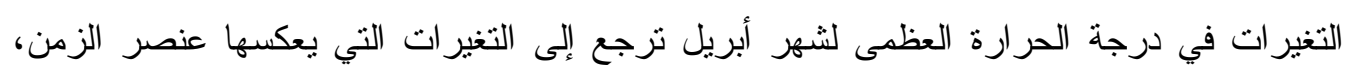
كما أن قيمة F المحسوبة وقيمتها (1.84) تشير إلى معنوية نموذج الانحدار الخطى البسيط في تمثيل

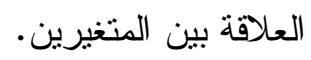

$$
\hat{y}=29.34+0.118 x_{i}
$$

$$
\mathrm{R}^{2}=(0.66) \quad \mathrm{F}=1.84
$$

\section{حيث :}

القيمة التقديرية لدرجة الحرارة العظمى لشهر أبريل بالدرجات المئوية.. : وحدات الزمن بالسنو ات من 1 إلى 27 سنة .

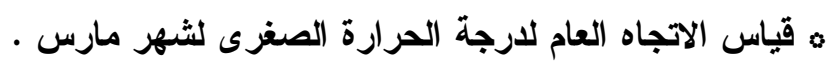

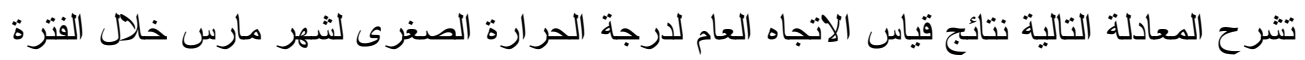

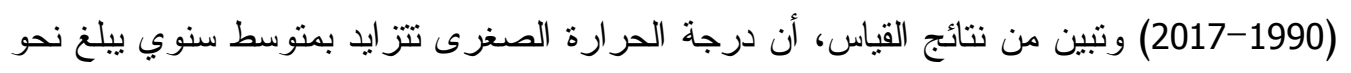
0.035 درجة مئوية، وأن أدنى درجة تتحقق تبلغ نحو 9.55 درجة مئوية، وأن كلا المؤشرين

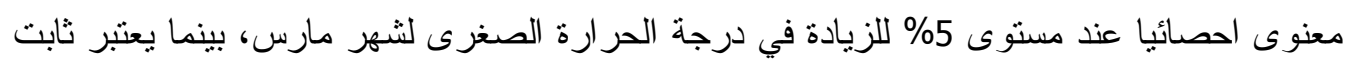

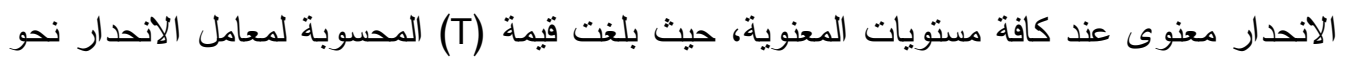

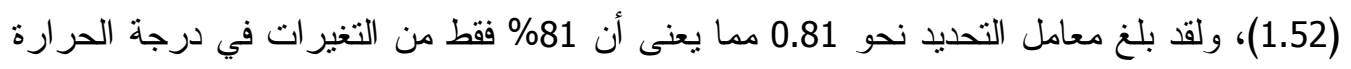

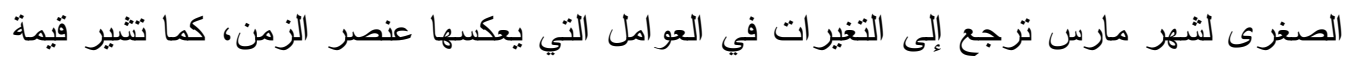

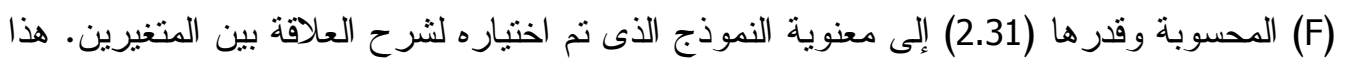

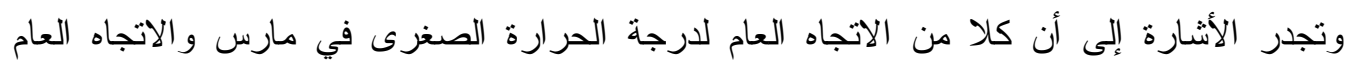

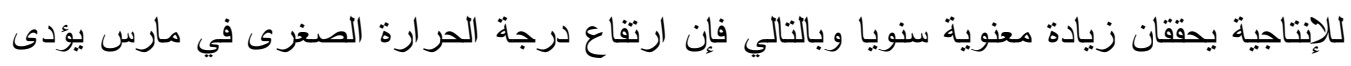




$$
\hat{y}=9.55+0.035 x_{i}
$$

$R^{2}=(0.81)$

$\mathrm{F}=2.31$

م قياس الاتجاه العام لدرجة الحرارة الصغرى لشهر أبريل .

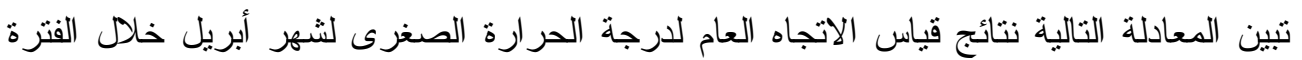

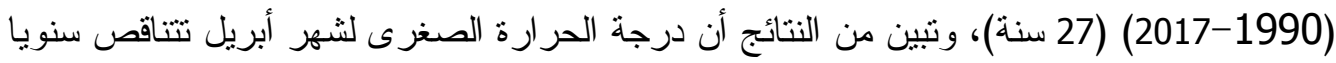

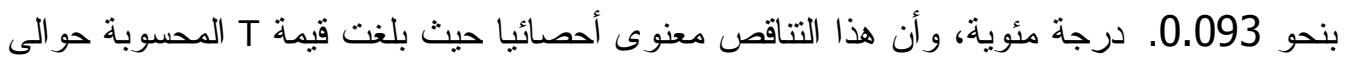

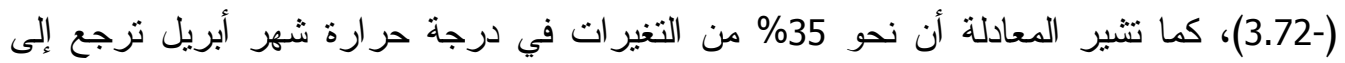

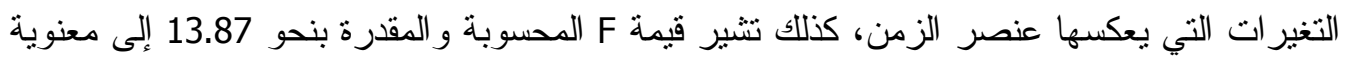
نموذج الانحدار الخطى في تمثيل العلاقة بين درجة الحر ارة الصغرى لأبريل و الزمن. $\hat{y}=13.31-0.093 x_{i}$

$R^{2}=(0.35)$

$$
F=13.87
$$

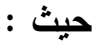

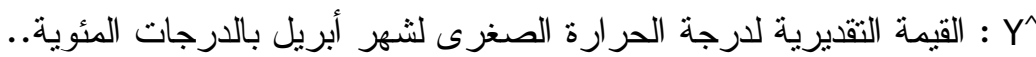
: وحدات الزمن بالسنو ات من 1 إلى 27 سنة . Xi

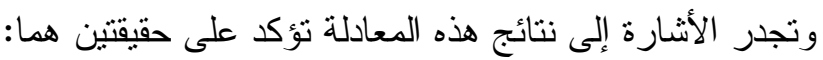

أن عنصر درجة الحرارة الصغرى هو العنصر الحرج في تقدير الإنتاجية الفدانية لمحصول القمح، حيث أنها تختلف في اتجاهها العام عن الاتجاه العام لإنتاجية القمح. أن شهر أبريل يعتبر هو الثهر الحرج لتحديد مستوى إنتاجية القمح.

\section{م قياس الاتجاه العام لمتوسط درجة الرطوبة النسبية لشهر مارس.}

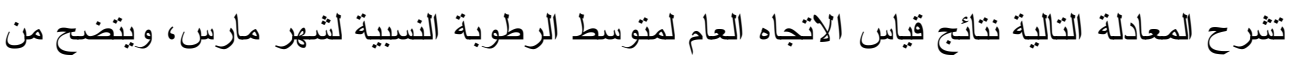
النتائج أن هناك زيادة سنوية تقدر بحو الي 0.64\% في درجة الرطوبة النسبية لثهر مارس، و أن هذه

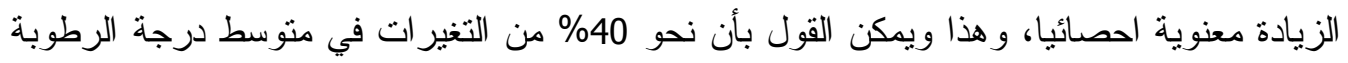

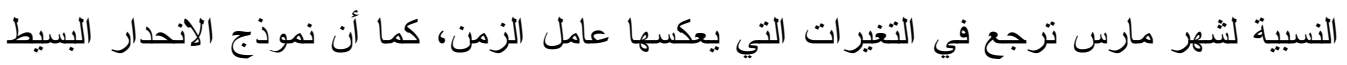
معنوى حيث قدرت قيمة F المحسوبة بنحو (17.52). ومن المؤكد أن عامل متوسط الرطوبة النسبية لثهر مارس ليس هو العنصر الحرج أو الثهر الحرج في التأثنر بالسالب على إنتاجية محصول وند $\hat{y}=39.54+0.64 X_{i}$

$R^{2}=(0.40)$

$$
\mathrm{F}=17.52
$$




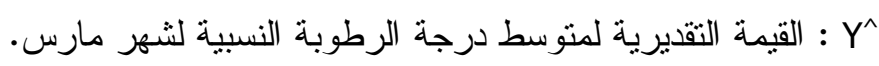

$$
\text { : وحدات الزمن بالسنو ات من } 1 \text { إلى } 27 \text { : }
$$

ه قياس الاتجاه العام لمتوسط درجة الرطوبة النسبية لثهر أبريل.

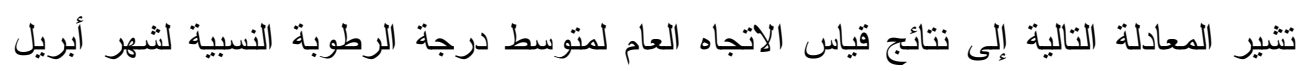

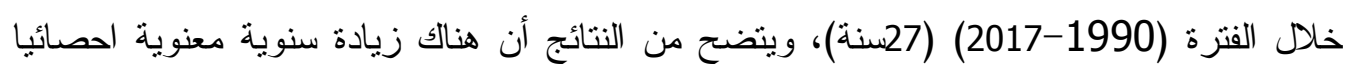

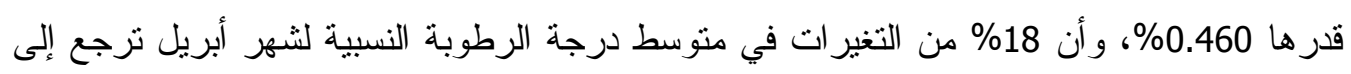
التغير ات التي يعكسها عنصر الزمن. كما تؤكد النتائج أن متوسط الرطوبة النسبية ليس عاملا حرجا في التأثير بالسالب على إنتاجية محصول القمح، خاصة في شهر أبريل.

$$
\hat{y}=39.45+0.460 x_{i}
$$

$$
\mathrm{R}^{2}=(0.18) \quad \mathrm{F}=5.73
$$

3. اختيار العنصر المناخى الحرج:

بالنظر الى نتائج قياس الاتجاه العام، يتضح ان نأثنير درجة الحرارة العظمى فى شهرى مارس

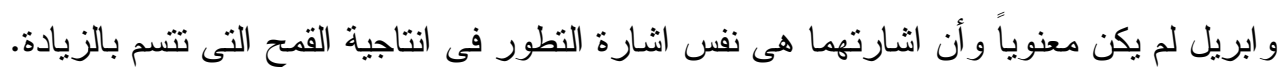

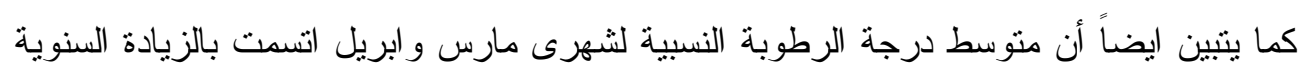

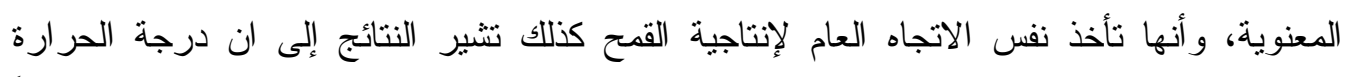

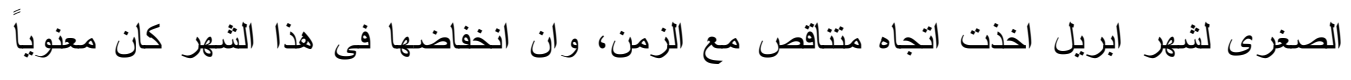

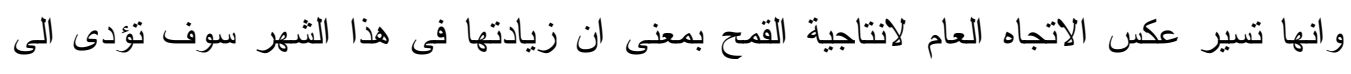

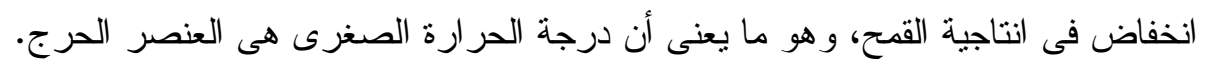

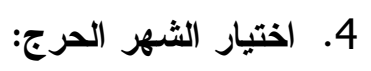

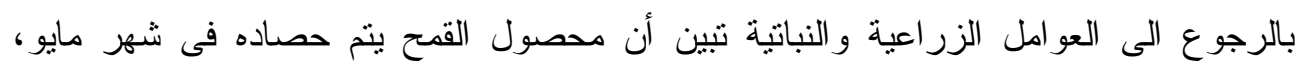

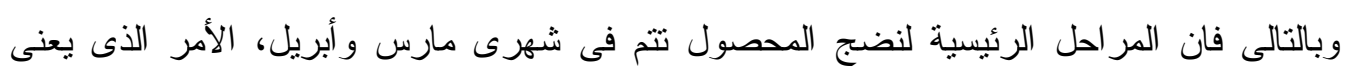
اختيار شهر أبريل ليكون هو الثهر الحرج فى تحديد العلاقة بين انتاجية القمح ودرجة الحرارة الصغرى.

\section{5. قياس العلاقة بين إنتاجية القمح ودرجة الحرارة الصغرى لثهر أبريل:}

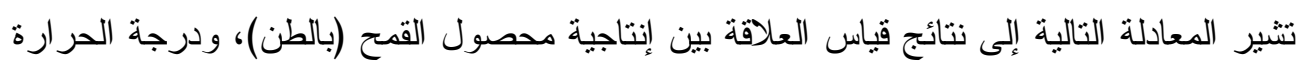

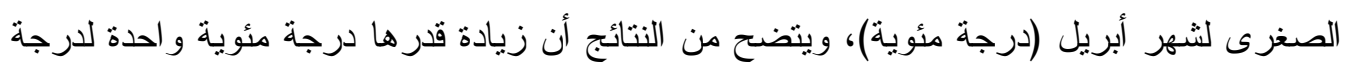

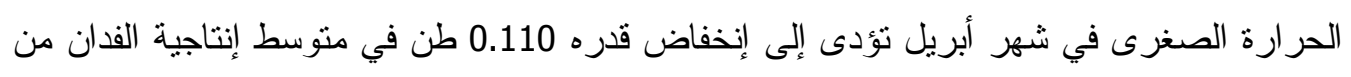

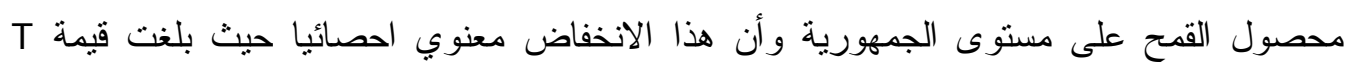
المحسوبة لمعامل الانحدار نحو(-4.37)، كما نثير قيمة معامل التحديد إلى أن نحو 42\% من 
التغيرات في إنتاجية محصول القمح تعود إلى التغيرات في درجات الحرارة الصغرى في شهر أبريل، كما ثبرر النتائج معنوية نموذج الانحدار الخطى البسيط في تمثيل العلاقة بين المتغيرين. $\hat{y}=3.93-0.110 x_{i}$

$R^{2}=(0.42)$ $F=19.12$

\section{حيث :}

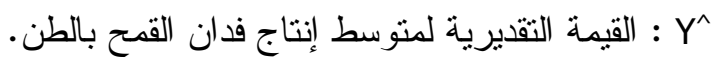

Xi : درجة الحرارة الصغرى لنهر أبريل من 1 إلى 27 : 27

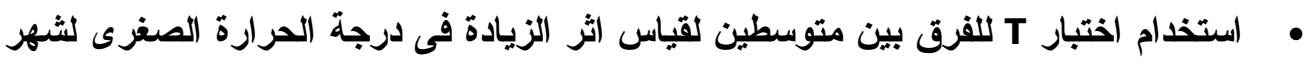

ابريل على انتاجية القمح:

تبرر لدر اسة تطور إنتاجية القمح خلال الفترة (1990-2017) أنه يمكن أن تكون هناك فئتان

للإنتاجية، الأولى تنخفض فيها الإنتاجية عن 2.46 طن للفدان، و الثانية التي تتضمن إنتاجيات 2.74 طن فأكثر • وتتضمن الفئة الأولى الفترة من (1990 - 2002) في حين تتضمن الإنته لفئة الثانية الفترة من ون (2003 - 2017) ولقد أجرى أختبار T للفرق بين منوسطي إنتاجية القمح في الفترتين، وتبين من فن

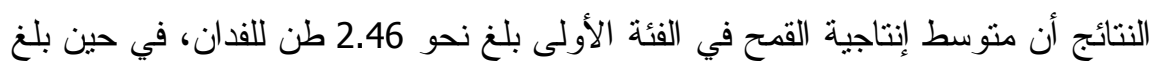

جدول رقم (1) نتائج اختبار T للفرق بين متوسطى الفئتين

\begin{tabular}{|c|c|c|c|c|c|}
\hline قيمة اختبار & $\begin{array}{l}\text { الخطأ المعيارى } \\
\text { SE }\end{array}$ & $\begin{array}{c}\text { الاحر اف المعيارى } \\
\text { SD }\end{array}$ & المتوسط & العدد & البيان \\
\hline \multirow{2}{*}{ 4.33- } & 0.061 & 0.221 & 2.462 & 13 & الفترة الأولى \\
\hline & 0.029 & 0.112 & 2.744 & 15 & الفترة الثانية \\
\hline
\end{tabular}

المصدر: جمعت وحسبت من الجدول رقم (3)

في الفئة الثانية نحو 2.74 طن للفدان، بزيادة تقدربحو الي 0.282 من الطن و أن هذه الزيادة معنوية

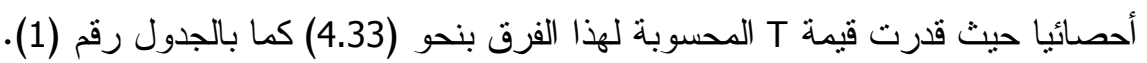
كما اجرى اختبار T للفرق بين منوسطى درجة الحرارة الصغرى لشهر أبريل وفقا لسنوات الفئتين، أي ضمت الفئة الأولى درجة الحرارة الصغرى لثهر أبريل في الفترة (1990-2002) بينما ضمت الفئة الثانية درجة الحر ارة الصغرى لثهر أبريل في الفترة (2003- 2017) للتأكد من نقطنين الأولى أن إنخفاض الإنتاجية في الفئة الأول يعزى إلى ارتفاع درجة الحرارة الصغرى، ولهئ والثانية تحديد الفرق في درجات الحر ارة المصاحب للإنخفاض في الإنتاجية و الجدول التالى يشرح النتائج. 
وتبرر النتائج بالجدول رقم (2) أن منوسط درجة الحرارة الصغرى لشهر أبريل في الفئة الأولى (الأقل إنتاجية) بلغ نحو 12.765 درجة، في حين بلغ في الفئة الثانية (الأعلى إنتاجية) نحو 11.257 ندانة

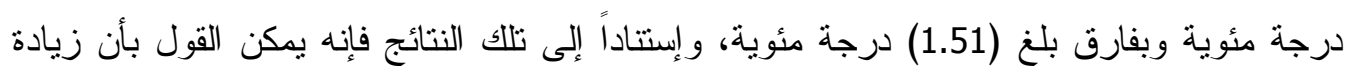

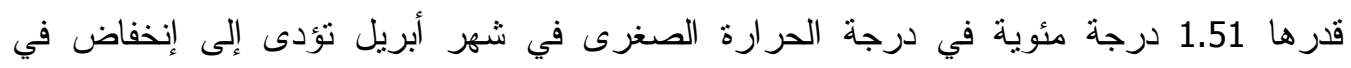
الإنتاجية يقدر بنحو 0.282 طن.

\section{• الآثار الاقتصادية المترتبة على ارتفاع درجات الحرارة الصغرى لثهر أبريل:}

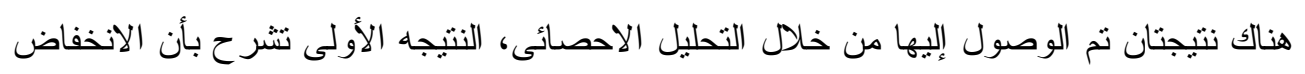

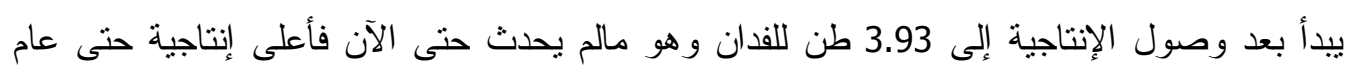
2017 بلغت 2.88 طن للفدان. أما النتيجة الثانية فيستلزم أن يمر في المستقبل نحو 10 سنو ات للتأكد من استمر ار الارتفاع خلال

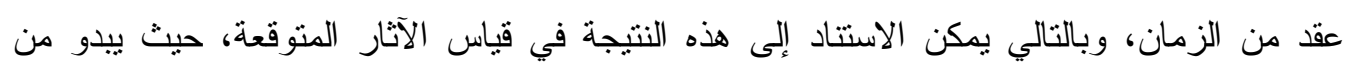

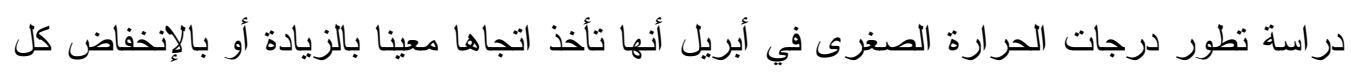
عشر سنوات تقريبا، فإذا حدثت هذه الزيادة خلال الفترة 2016 حتى 2030 فإن إنتاجية المحصول فئرل سوف تتخفض بنسبة 11.1\%

\section{جدول رقم (2) نتائج اختبار T للفرق بين متوسطى درجة الحرارة الصغرى لثهر أبريل}

\begin{tabular}{|c|c|c|c|c|c|}
\hline قيمة اختبار & $\begin{array}{l}\text { المعيارى } \\
\text { SE } \\
\end{array}$ & $\begin{array}{c}\text { المعيارى } \\
\text { SD } \\
\text { SD }\end{array}$ & المتوسط & العدد & البيان \\
\hline \multirow{2}{*}{3.69} & 0.38 & 1.37 & 12.77 & 13 & متوسط الحرارة الصغرى \\
\hline & 0.19 & 0.73 & 11.26 & 15 & متوسط الحرارة الصغرى \\
\hline
\end{tabular}

المصدر: جمعت وحسبت من الجدول رقم (3) 
الجدول رقم (3) المؤشرات الإنتاجية لمحصول القمح ودرجات الحرارة الصغرى والعظىى

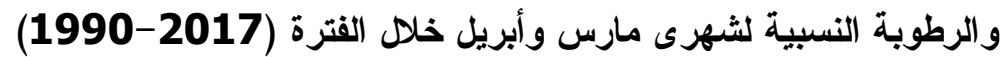

\begin{tabular}{|c|c|c|c|c|c|c|c|}
\hline شالنسية فئة البربة & 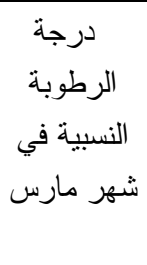 & الصر ألير شرة & شهر أبرى فيل & في الصر ارة & 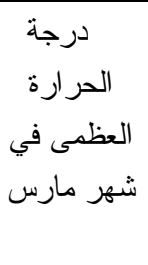 & محصول & السنو ات \\
\hline 32.9 & 40.2 & 13.9 & 28.4 & 9.1 & 22.5 & 2.33 & 1990 \\
\hline 42.9 & 37.6 & 14.6 & 29.1 & 11.2 & 24.9 & 2.16 & 1991 \\
\hline 35.2 & 38.4 & 12.0 & 26.7 & 8.8 & 22 & 2.36 & 1992 \\
\hline 34.2 & 36.3 & 12.9 & 28.1 & 8.6 & 22.4 & 2.37 & 1993 \\
\hline 39.3 & 39.5 & 14.4 & 29.7 & 9.6 & 22.6 & 2.24 & 1994 \\
\hline 34.9 & 40.1 & 12.4 & 27.2 & 10.3 & 24.0 & 2.28 & 1995 \\
\hline 38.5 & 34.7 & 11.7 & 26.8 & 10.2 & 23.4 & 2.37 & 1996 \\
\hline 35.8 & 38.2 & 11.7 & 25.9 & 8.2 & 21.8 & 2.35 & 1997 \\
\hline 38.2 & 44.4 & 15.1 & 29.3 & 9.1 & 21.3 & 2.53 & 1998 \\
\hline 36.9 & 41.5 & 12.9 & 27.6 & 10.6 & 23.8 & 2.67 & 1999 \\
\hline 54.3 & 58.3 & 11.7 & 34.8 & 9.1 & 29.6 & 2.80 & 2000 \\
\hline 56.5 & 57.2 & 11.6 & 35.9 & 12.1 & 33.8 & 2.76 & 2001 \\
\hline 54.9 & 56.3 & 10.8 & 35.7 & 10.8 & 31.3 & 2.79 & 2002 \\
\hline 54.4 & 56.6 & 11.1 & 36.5 & 8.6 & 28.8 & 2.73 & 2003 \\
\hline 54.2 & 55.4 & 11.4 & 33.7 & 10.8 & 33.8 & 2.76 & 2004 \\
\hline 53.5 & 54.03 & 10.6 & 35.3 & 10.3 & 31.1 & 2.73 & 2005 \\
\hline 55.1 & 53.6 & 11.2 & 34.7 & 9.9 & 31.8 & 2.71 & 2006 \\
\hline 61.5 & 58.9 & 11.6 & 35.3 & 10.5 & 30.9 & 2.75 & 2007 \\
\hline 54.7 & 54.5 & 10.9 & 37.5 & 11.4 & 34.7 & 2.73 & 2008 \\
\hline 54.2 & 55.1 & 10.8 & 33.8 & 9.9 & 32.1 & 2.71 & 2009 \\
\hline 54.9 & 55.9 & 12.2 & 33.6 & 11.5 & 35.4 & 2.39 & 2010 \\
\hline 54.8 & 58.7 & 11.4 & 25.8 & 10.6 & 22.3 & 2.87 & 2011 \\
\hline 52.6 & 56.4 & 10.9 & 28.2 & 11.2 & 23.7 & 2.78 & 2012 \\
\hline 42.3 & 41.2 & 9.5 & 27.6 & 8.6 & 26.5 & 2.8 & 2013 \\
\hline 41.2 & 54.9 & 10.9 & 29.3 & 10.7 & 24.8 & 2.73 & 2014 \\
\hline 41.2 & 48.3 & 11.7 & 34.0 & 9.8 & 24.6 & 2.77 & 2015 \\
\hline 39.1 & 54.1 & 12.6 & 31.04 & 10.3 & 25.3 & 2.8 & 2016 \\
\hline 42.9 & 48.1 & 12.0 & 28.2 & 9.8 & 23.9 & 2.9 & 2017 \\
\hline
\end{tabular}

وزارة الزراعة واستصلاح الأراضى - قطاع الثئون الاقتصادية- الإدارة المركزية للاقتصاد الزراعي و الإحصاء -

نشرة الاقتصاد الزر اعي - اعداد متقرقة.

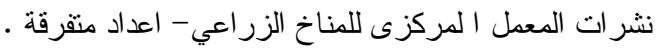


6. قياس الآثار المترتبة على انخفاض انتاجية القمح بارتفاع درجة الحرارة الصغرى فى شهر (بريل.

تم اجر اء عدد من السيناريوهات التى نوضح تأثثير التغير فى درجة الحرارة الصغرى على

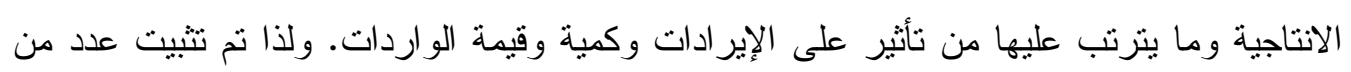

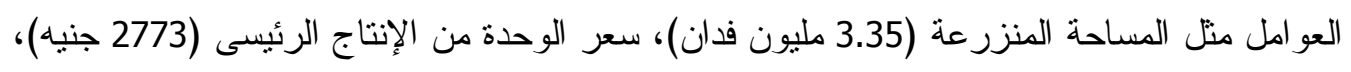

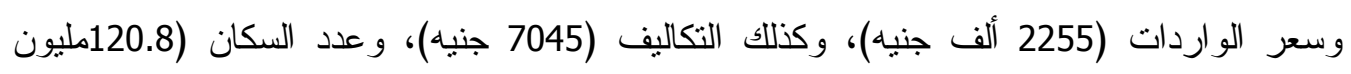

نسمة)، ويوضح الجدولين (4)، (5):

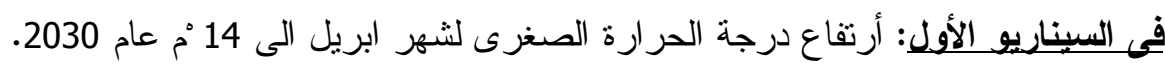
و هذا يؤدى الى انخفاض إنتاجية محصول القمح بنسبة 17.01\% أى نصل الى نحو 2.39 طن/فدان، وبالتالى ينخفض الإنتاج الكلى إلى 8.01 مليون طن، والإير ادلى الكلى الى حوالى 8449

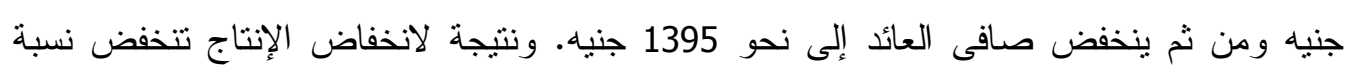

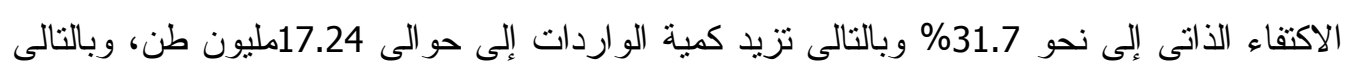
تزيد فاتورة الو اردات إلى حوالى 38.87 مليار جنيه.

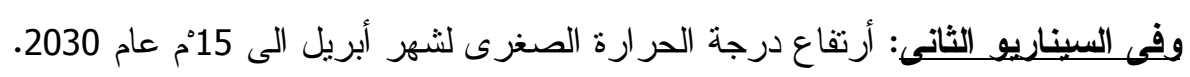

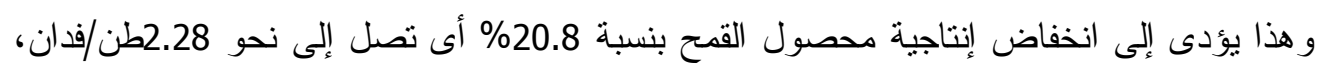
وبالتالى ينخفض الإنتاج الكلى إلى 7.63 مليون طن، و الإير اد الكلى إلى حو الى لى 8144 جنيه ومن ثن إنى

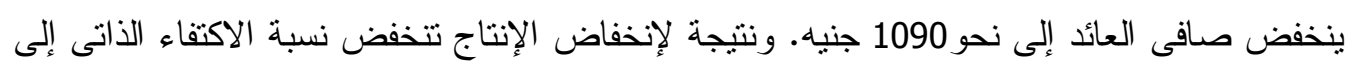

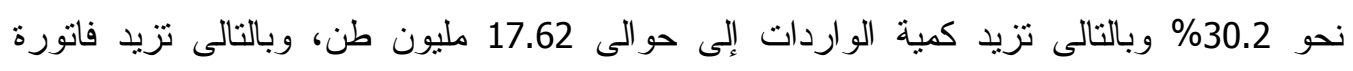
الو اردات إلى حو الى 39.73مليار جنيه.

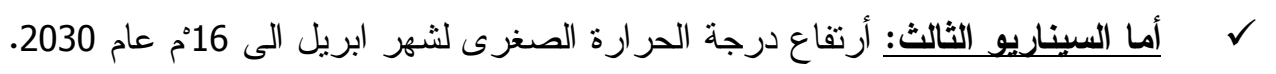

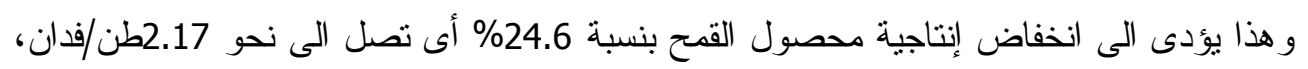

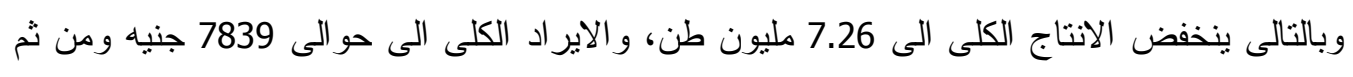

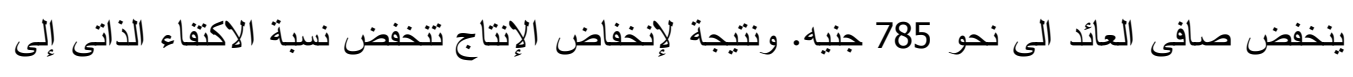

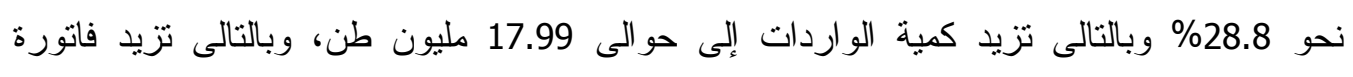
الو اردات إلى حو الى 40.56 مليار جنيه.

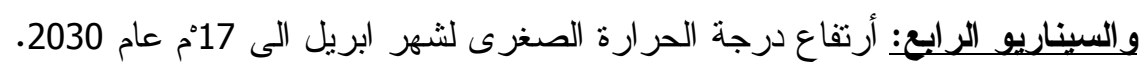

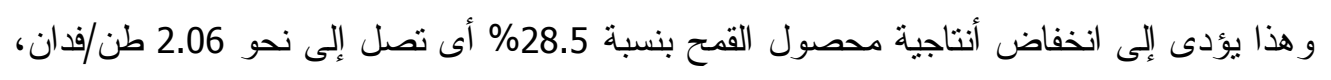

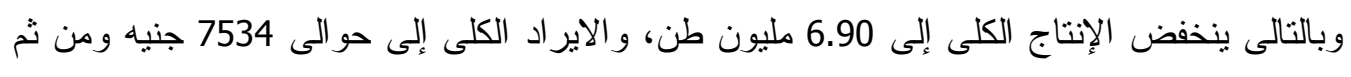
ينخفض صافى العائد إلى نحو 480 جنيه. ونتيجة لإنخفاض الإنتاج تنخفض نسبة الاكتفاء الذاتى إلى لى لئى

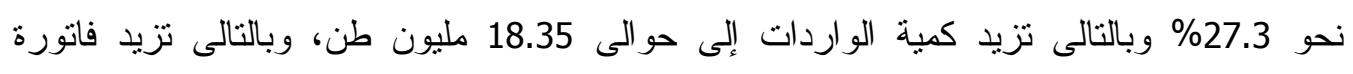
الو اردات إلى حو الى 41.37 مليار جنيه. 
جدول رقم (4) السيناريوهات الأربعة والمتغيرات الأساسية لمحصول القمح على مستوى المزرعة

\begin{tabular}{|c|c|c|c|c|c|c|}
\hline \multicolumn{4}{|c|}{2030} & \multirow{3}{*}{2016} & \multirow{3}{*}{ الوحدة } & \multirow{3}{*}{ 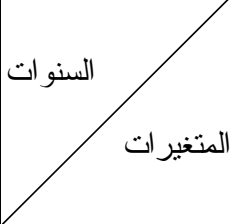 } \\
\hline السيناريو & السيناريو & السيناريو & السيناريو & & & \\
\hline الر ابع & الثالث & الثانى & الأول & & & \\
\hline \multirow{2}{*}{2.06} & \multirow{2}{*}{2.17} & \multirow{2}{*}{2.28} & \multirow{2}{*}{2.39} & \multirow{2}{*}{2.88} & \multirow{2}{*}{ طن/فدان } & منوسط انتاجية \\
\hline & & & & & & الس ال (ربيسى) \\
\hline \multirow{2}{*}{2.76} & \multirow{2}{*}{2.76} & \multirow{2}{*}{2.76} & \multirow{2}{*}{2.76} & \multirow{2}{*}{2.76} & \multirow{2}{*}{ طن/فدان } & متوسط انتاجية الفدان \\
\hline & & & & & & \\
\hline \multirow[b]{2}{*}{2773} & \multirow[b]{2}{*}{2773} & \multirow[b]{2}{*}{2773} & \multirow[b]{2}{*}{2773} & \multirow[b]{2}{*}{2773} & \multirow{2}{*}{ جنيه/طن } & سعر الوحدة من \\
\hline & & & & & & الانتاج الرئيسى \\
\hline \multirow[b]{2}{*}{660} & \multirow[b]{2}{*}{660} & \multirow[b]{2}{*}{660} & \multirow[b]{2}{*}{660} & \multirow[b]{2}{*}{660} & \multirow{2}{*}{ جنيه/طن } & سعر الوحدة من \\
\hline & & & & & & الانتاج الثانوى \\
\hline 7534 & 7839 & 8144 & 8449 & 9807 & جنيه & إجمالى الإير اد الكلى \\
\hline \multirow[b]{2}{*}{7054} & \multirow[b]{2}{*}{7054} & \multirow[b]{2}{*}{7054} & \multirow[b]{2}{*}{7054} & \multirow[b]{2}{*}{7054} & \multirow[b]{2}{*}{ جنيه } & اجمالى التكاليف \\
\hline & & & & & & \\
\hline 480 & 785 & 1090 & 1395 & 2753 & جنيه & صافى العائد للفدان \\
\hline
\end{tabular}

المصدر: وزارة الزراعة واستصلاح الأراضى - قطاع الثئون الاقتصادية- الإدارة المركزية للاقتصاد الزراعي والإحصاء - نشرة الاقتصاد الزر اعي - اعداد متفرقة. 
جدول رقم (5) السيناريوهات الأربعة والمتغيرات الأساسية

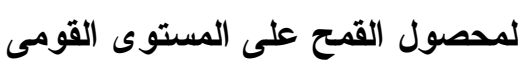

\begin{tabular}{|c|c|c|c|c|c|c|}
\hline \multicolumn{4}{|c|}{2030} & \multirow{3}{*}{2016} & \multirow{3}{*}{ 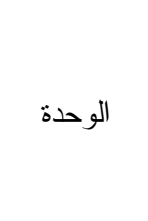 } & \multirow{3}{*}{ السنوات } \\
\hline السيناريو & السيناريو & السيناريو & السيناريو & & & \\
\hline الر ابع ل & الثالث الث & الثانى الثى & الأول & & & \\
\hline 2.06 & 2.17 & 2.28 & 2.39 & 2.88 & طن/فدان & متوسط الإنتاجية \\
\hline 3.35 & 3.35 & 3.35 & 3.35 & 3.35 & مليون فدان & المساحة المنزرعة \\
\hline 6.90 & 7.26 & 7.63 & 8.01 & 9.64 & مليون طن & الإنتاج الكلى \\
\hline 209 & 209 & 209 & 209 & 209 & كجم & من من إجمالي الاستهلالك الفرد \\
\hline 1.02 & 1.02 & 1.02 & 1.02 & & $\%$ & معدل النمو السكانى \\
\hline 120.8 & 120.8 & 120.8 & 120.8 & 93.44 & مليون نسمة & عدد السكان \\
\hline 25.25 & 25.25 & 25.25 & 25.25 & 19.59 & مليون طن & اجمالى الإستهلالك \\
\hline 27.3 & 28.8 & 30.2 & 31.7 & 49.2 & $\%$ & \\
\hline 18.35 & 17.99 & 17.62 & 17.24 & 9.95 & مليون طن & إجمالى الواردات \\
\hline 2255 & 2255 & 2255 & 2255 & 2255 & بالألف جنيه & سعر الواردات \\
\hline 41.37 & 40.56 & 39.73 & 38.87 & 22.44 & مليون جنيه & قيمة الواردات \\
\hline
\end{tabular}

المصدر: - - - n

- وزارة الزراعة واستصلاح الأراضى - قطاع الثئون الاقتصادية- الإدارة المركزية للاقتصاد الزراعي والإحصاء - نشرة الاقتصاد الزر اعي - أعداد متفرقة. - الجهاز المركزي للتعبئة العامة والاحصاء، موقع شبكة مركز المعلومات. 


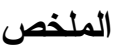

يُمنتل القمح أهم الحاصلات الثتتية على الإطلاق، ويعتبر الخبز الناتج عنه أهم السلع الغذائية المصرية التى يعتمد عليها المصريون فى غذائهم اليومى، وتستورد منه مصر كميات كبيرة نصل ولئل

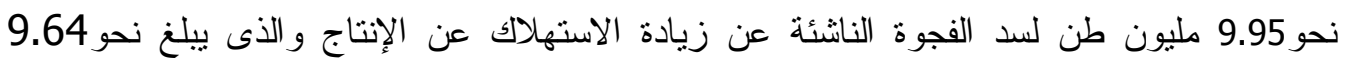
مليون طن عام2016 ويمثل الدعم الموجه له نسبة لا تقل عن 70\% من قيمة الدعم الغذائى والذي لادي

$$
\text { تعدى } 22.442 \text { مليار جنية عام } 2016
$$

و أستهدفت الدر اسة قياس الاتجاه العام لعناصر المناخ (درجة الحرارة العظمى، درجة الحرارة الصغرى، متوسط درجة الرطوبة النسبية) وذلك فى شهور نمو المحصول، مع تحديد العلاقات الكمية بين العنصر المناخى والثهر الحرج و إنتاجية المحصول، مع قياس الآثار الاقتصادية المنوقعة لعلاقة التغير ات المناخية و إنتاجية المحصول على مستوى المزرعة و على المستوى القومى.

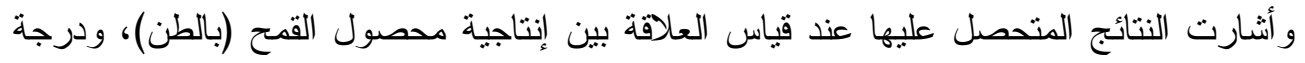
الحر ارة الصغرى لثهر أبريل، أن زيادة قدرها درجة مئوية واحدة لارجة الحرارة الصغرى فى لئه

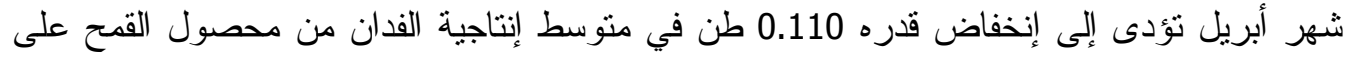

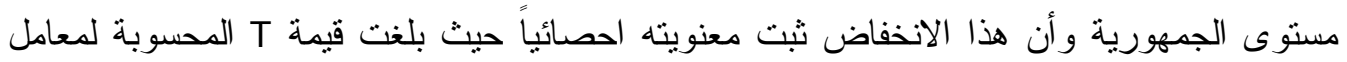
الانحدار نحو (-4.37)، كما تُشير قيمة معامل التحديد إلى أن 42\% من الانغ التغير ات فئه في إنتاجية محصول

$$
\text { القمح تعود إلى التغير ات في درجات الحر ارة الصغرى في شهر أبريل. }
$$

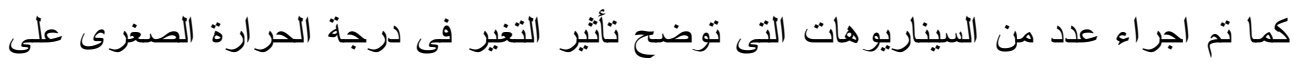

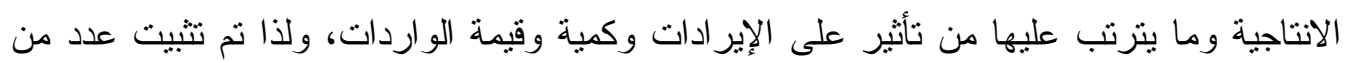

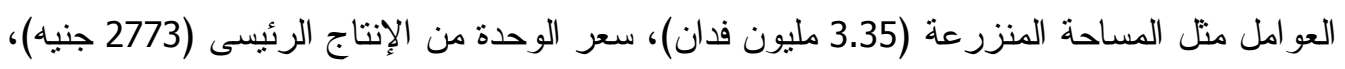

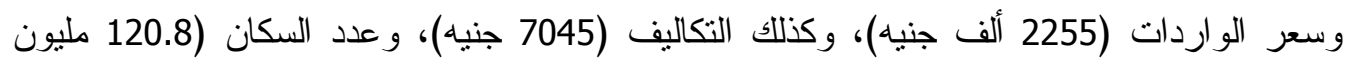

و أوصت الدر اسة بالاهتمام الثديد بجمع وتحليل بيانات المناخ على مستوى المر اكز و المحافظات

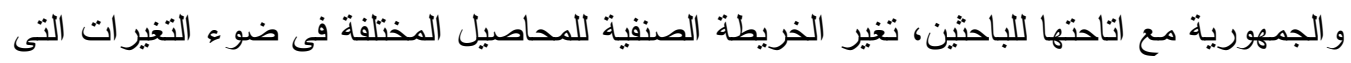
حدثت فى عناصر المناخ أو تلك التغير ات المتوقع حدوثها، اعداد بر امج لتربية اصناف المحاصيل

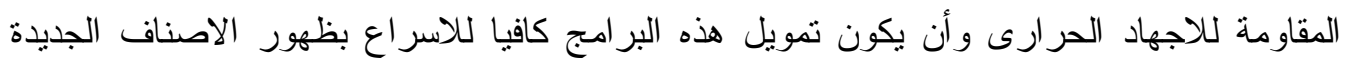




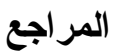

1) أيمن فريد أبو حديد " التغيرات المناخية المستقبلية وأثرها على قطاع الزراعة في مصر وكيفية مواجهتها "- مركز المعلومات و التغير ات المناخية أكتوبر 2009. 2) الجهاز المركزي للتعبئة العامة والاحصاء، موقع شبكة مركز المعلومات.

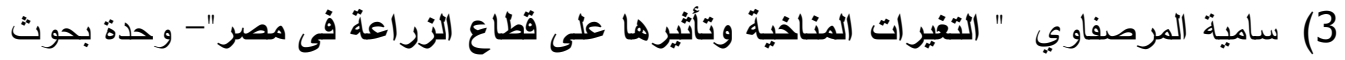
الأرصاد الجوية الزر اعية و التغير فى المناخ، شبكة اتصال التتمية الزر اعية الريفية 2007.

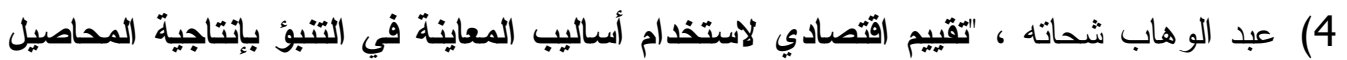
الزراعية"، رسالة ماجستير، كلية الزر اعة، قسم الاقتصاد الزر اعى، جامعة عين شمس، 1996.

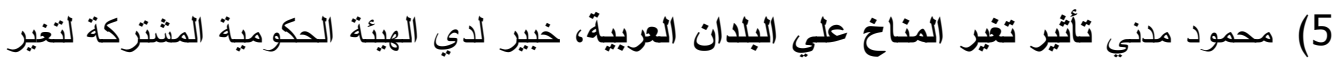
المناخ، ونائب مدير المختبر المركزي الزر اعي للتغير ات المناخية في القاهرة. 6) نشرات المعمل المركزى للمناخ الزر اعي- اعداد متفرقة .

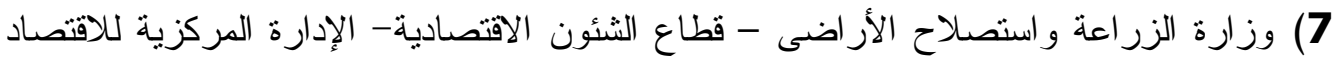
الزر اعي و الإحصاء - نشرة الاقتصاد الزر اعي - اعداد متفرقة.

8) Maez,M.M., Modeling of growth and geographical distribution of some crop plants in relation to expected climate change. M.Sc. Thesis, Fac. of Science., Cairo Univ.,2007. 
